\title{
“TODAS AS LIBERDADES SÃO IRMÃS": OS CAIXEIROS E AS LUTAS DOS TRABALHADORES POR DIREITOS ENTRE O IMPÉRIO E A REPÚBLICA
}

"All freedoms are equal": the salesmen and the workers' fights for rights between the Empire and the Republic

FABIANE POPINIGIS

http://dx.doi.org/10.1590/S2178-14942016000300005

Fabiane Popinigis é mestre e doutora em História pela Universidade Estadual de Campinas e professora adjunta do Departamento de História do Programa de Pós-Graduação em História da Universidade Federal Rural do Rio de Janeiro (fpopinigis@ gmail.com).

Artigo recebido em 3 de agosto e aprovado para publicação em 26 de setembro de 2016. 


\title{
RESUMO
}

0 objetivo deste artigo é estabelecer um diálogo com a historiografia recente sobre temas clássicos da história do trabalho - como as diversas formas de exploração do trabalho, as lutas por direitos e cidadania e a organização dos trabalhadores - a partir da experiência de uma vasta categoria de trabalhadores urbanos. As lutas dos empregados no comércio por direitos através do associativismo, do teatro, da imprensa e da municipalidade fizeram parte do processo de organização dos movimentos sociais no Rio de Janeiro na década de 1880, e apareceram como modelos de uma cidadania republicana que, por sua vez, excluía outras categorias de trabalhadores.

Palavras-Chave: luta por direitos, cidadania, trabalho escravo, trabalho livre, pós-abolição, empregados no comércio.

\begin{abstract}
This article looks for a dialogue with the recent historiography dealing with classical themes of the history of work - such as the various forms of work exploitation, the fights for rights and citizenship and the organization of workers - focusing on the experience of a large category of urban workers. The fight of the salesmen for rights held through associations, the theatre, the press and the municipality were part of the organization of social movements in Rio de Janeiro in the 1880's and became a model of a republican citizenship that excluded other categories of workers.
\end{abstract}

KeYwORDs: fight for rights, citizenship, slave work, free work, salesmen.

\section{RÉSUMÉ}

Le but de cet article est d'établir un dialogue avec l'historiographie récente consacrée à des thèmes classiques de l'histoire du travail - tels que les différentes formes d'exploitation du travail, les luttes pour des droits et la citoyenneté, et l'organisation des travailleurs - en examinant l'expérience d'une vaste catégorie de travailleurs urbains. Les luttes des employés du commerce pour leurs droits menées à l'aide de l'associativisme, le théatre, la presse et la municipalité ont fait partie du processus d'organisation des mouvements sociaux à Rio de Janeiro aux années 1880 et sont devenues des modèles d'une citoyenneté républicaine qui excluait d'autres catégories de travailleurs.

Mots-clés: lutte pour droits, citoyenneté, travail esclave, travail libre, employés du commerce. 


\section{INTRODUÇÃO}

$\mathrm{D}$ ata de 1826 a formação da primeira sociedade de auxílio-mútuo de caixeiros (logo após a Independência, que ocorreu em 1822) e de 1852 o primeiro projeto de postura pela regulamentação do horário de trabalho no comércio (logo após a abolição do tráfico atlântico de escravos e da aprovação do código comercial em 1850). ${ }^{1}$ Nas décadas de 1880 e 1890 surgiram associações com o objetivo explícito de obter o que ficou conhecido como "fechamento das portas das casas comerciais" em determinados dias e horários, não apenas através de acordos com os patrões, mas também procurando a intervenção dos poderes públicos na questão. Assim, o movimento caixeiral integrou-se ao processo mais amplo de engajamento político nas lutas sociais, como o abolicionismo, o republicanismo e o movimento operário. 0 teatro e a imprensa, além da comunicação direta com a Câmara, através de cartas e petições, constituíram amplos canais de debate e reivindicação desses trabalhadores aos poderes públicos por direitos e cidadania.

A abordagem aqui proposta implica dialogar com três elementos de interpretação da sociedade brasileira: 1. Do ponto de vista político, o das referências ao liberalismo oligárquico, um sistema em que o coronelismo e as relações de clientelismo teriam transformado os trabalhadores em passivos espectadores do processo político; 2. Da perspectiva econômica, o da "transição do trabalho escravo para o trabalho livre" e sua centralidade para o desenvolvimento capitalista; 3. Da história do movimento operário, como o momento de ascensão e queda de um sindicalismo atuante e autônomo, em detrimento de outras práticas e formas de lutas. Assim, antes de analisar as estratégias dos caixeiros para colocar em pauta as suas reivindicações, faremos um rápido panorama sobre a centralidade desses temas para a história social no Brasil - sem a intenção, obviamente, de dar conta dessa vasta produção nestas poucas páginas.

\section{HISTÓRIA E HISTORIOGRAFIA - SOBRE CIDADANIA E PARTICIPAÇÃO POPULAR NAS LUTAS POLÍTICAS}

partir dos anos 1980 e 1990, sob a influência da história social inglesa e da micro-
-história italiana, pesquisas sobre os anos finais da escravidão e o período inicial da 
Primeira República no Brasil ganharam novo impulso. 0 cotidiano de homens e mulheres pobres nas cidades e no campo tornou-se tema central de investigação com intensa ênfase na pesquisa histórica sobre suas condições de vida e trabalho, cultura e organização familiar para compreender processos históricos mais amplos. A história da classe trabalhadora - que na produção militante e acadêmica anterior foi muitas vezes caracterizada pela sua incapacidade política - passou a ser enfocada não apenas pelo viés de suas greves e lutas sindicais, mas também através de suas festas, momentos de sociabilidade e condições de moradia como parte essencial de sua experiência, na construção de elementos simbólicos de identidades cruzadas (Silva, 1984; Chalhoub, 2001; Abreu, 1989; Sohiet, 1989).

Em relação direta com a circulação da obra de E. P. Thompson e a criação e ampliação dos programas de pós-graduação em história e com as lutas pela redemocratização no país, os pesquisadores se concentraram em analisar experiências de exploração compartilhadas pelos trabalhadores e suas culturas de classe. Finalmente, os trabalhadores ganharam destaque não por sua ausência de cidadania, mas pela diversidade cultural, por suas práticas associativas e por sua ação política, entendida aqui de forma ampla (Lopes, 1976; Hall \& Pinheiro, 1985; Sader et al., 1983; Fortes et al., 1999; Batalha et al., 2004). Quase ao mesmo tempo, uma profícua historiografia da escravidão tratou das experiências de homens e mulheres escravizados como sujeitos históricos: laços familiares, relações de trabalho, condições de moradia, irmandades e festas, construção de identidades e redes de solidariedade. As fugas, as revoltas e as greves foram analisadas lado a lado com outras estratégias cotidianas de negociação e conflito, até mesmo o uso da lei pelos escravos na conquista da liberdade ou por espaços de autonomia (Soares, 2007; Reis, 1986; Chalhoub, 1990; Machado, 1998; Castro, 1998; Slenes, 1999; Gomes, 2005; Reis \& Silva, 1989). Assim, procurava-se compreender as lutas de homens e mulheres escravizados, libertos, livres e pobres não mais como meras reações à opressão vinda de cima, mas como ações orientadas por estratégias e projetos dos sujeitos envolvidos nos seus próprios termos. Os trabalhadores, portanto, livres ou escravizados passaram a ser vistos como agentes de sua própria história.

Como resultado desses debates combinados com o intenso trabalho nos arquivos, temas clássicos do recorte político tradicional da Primeira República foram revisitados numa perspectiva de história social: de um lado, o coronelismo reapareceu como espaço de disputas e da luta de classes, no qual a cultura, as estratégias, as motivações sociais em relação aos limites da liberdade tornaram-se objetos de interesse para a compreensão do funcionamento do sistema político; de outro lado, as relações raciais e de gênero passaram a ser pensadas não apenas como empecilhos à formação de culturas de classe, mas como parte integrante e constituinte desse processo (Machado, 2004; Cruz, 2000; Schettini, 2006; Nascimento, 2008; 
Abreu \& Gomes, 2009). Essas questões, especificamente concentradas nos estudos sobre a Primeira República, foram poucas vezes levadas em conta nas análises de balanço.

A isso se deve, em parte, que a história do trabalho tenha permanecido predominantemente ligada às experiências coletivas dos trabalhadores "livres" qualificados e organizados, enquanto a pesquisa a respeito de grande parte dos trabalhadores escravos no Brasil do século XIX ficou a cargo dos historiadores da escravidão. Desenvolveram-se campos de estudo em paralelo e quase sem diálogo, identificados por diversos balanços historiográficos, que chamaram a atenção para a necessidade de uma maior aproximação entre eles. Mais recentemente, alguns autores têm procurado entrelaçar pesquisas e abordagens que levem em conta as lutas de escravos e libertos ao longo do século XIX para a formação da classe trabalhadora no país (Lara, 1998; Gomes, 2004; Chalhoub \& Silva, 2009; Gomes \& Negro, 2006; Pereira, 2002; Mattos, 2008).

Ainda há um longo caminho a percorrer nesse sentido, pois um vasto contingente de trabalhadores até o início do século XX, como os empregados no comércio e os trabalhadores domésticos, por exemplo, permaneceu pouco investigado e ausente das análises mais gerais sobre a história do trabalho no Brasil. Atualmente tem havido um significativo aumento do interesse de jovens pesquisadores pela história do serviço doméstico, no compasso das recentes vitórias do movimento sindical das empregadas domésticas na aprovação de leis trabalhistas equiparáveis às de outras categorias. No caso da história do trabalho, esse interesse também sinaliza uma crescente preocupação com a integração das relações raciais e de gênero à história da classe trabalhadora (Salgueiro, 2005; Popinigis \& Schettini, 2009; Souza, 2011; Farias, Gomes \& Xavier, 2012; Costa, 2015). Para uma compreensão mais acurada da experiência histórica desses homens e mulheres no pós-abolição, portanto, é preciso integrar as dimensões de classe, raça e gênero às análises, não como excludentes ou contraditórias, mas de forma relacional, com sobreposições e intercalações em constante movimento.

A contribuição teórica e metodológica desses estudos, ao investigar as variadas dimensões do trabalho doméstico, remunerado ou não, e dos trabalhadores "não qualificados" - escravos, homens livres pobres e a maior parte das mulheres da classe trabalhadora - contrapõe-se à ideia da existência de uma "transição do trabalho escravo para o livre" expressa na fórmula mais tradicional da "substituição da mão de obra" na crise das sociedades escravistas. Tal interpretação pressupõe que o pleno desenvolvimento do capitalismo e de um mercado de trabalho "livre" era incompatível com o trabalho escravo, e se formaria apenas após a abolição, dando origem à classe operária e à luta de classes. A suposta "atipicidade" da classe operária brasileira viria, nessa interpretação, do fato de que a longa vigência do sistema escravista no Brasil havia impedido a formação de uma classe operária combativa e com 
forte identidade de classe, capaz de criar greves e movimentos de contestação significativos capazes de causar sérias ameaças à ordem estabelecida (Kovarick, 1987; Cardoso, 1961).

Esse modelo, que sugere linearidade e previsibilidade no processo de passagem de um modo de produção a outro, e segundo o qual o escravo seria necessariamente substituído pelo assalariado livre, impõe referências externas ao processo histórico ocorrido em várias regiões das Américas e do Caribe, e especificamente do Brasil, onde se verificava uma grande diversidade do emprego da mão de obra intercambiável: homens livres pobres e expropriados, trabalhadores por contrato, parceria, aprendizagem, escravos alugados, africanos livres, escravos vivendo sobre si e recebendo salários. Ou seja, havia um mercado de trabalho formado no Brasil do oitocentos, no qual proprietários, senhores e o próprio Estado buscavam formas alternativas de utilizar diversos tipos de mão de obra barata, sobretudo não assalariada (Mamigonian, 2005).

\section{Os TRABALHADORES E A CÂMARA MUNICIPAL, "ÓRGÃO PROTETOR NATO DO POVO"}

tualmente novas pesquisas no campo da história social permitem avançar na dire-
çán compreensão mais complexa e matizada deste importante período de redefinição das relações de trabalho no Brasil no último quartel do oitocentos e no início do século XX. E não é a toa que isso ocorre justamente a partir de estudos que privilegiam as relações estabelecidas entre as Câmaras Municipais e os trabalhadores e/ou outras esferas administrativas. Tal abordagem tem várias vantagens, entre elas a relativa abundância de fontes produzidas (cartas e pedidos enviados, editais, posturas, projetos e correspondência com as outras instâncias) e a possibilidade de encontrar os trabalhadores em ação na reivindicação de seus direitos ou expressando noções do justo com uma considerável margem de ação. Esses estudos recentes têm enfocado as relações com a municipalidade e trazem uma releitura da ênfase no controle social da vida e do corpo dos trabalhadores e das classes populares mostrando que, se as posturas, determinações e fiscalização da Câmara são parte de um processo de controle e vigilância dos trabalhadores, por outro lado também são espaço de demanda e embates que mobilizam os recursos oferecidos por essas mesmas esferas. Os embates se pautam em argumentos diversos, que vão desde o direito ao trabalho, passando pelo combate aos monopólios e aos atravessadores, pela carestia, o aumento de impostos até a reivindicação de direitos pelos cidadãos (Schettini \& Terra, 2013).

Nessa perspectiva, portanto, o Estado não aparece como monolítico, demiurgo ou onipresente, imbuído de políticas e projetos prontos e acabados para as classes populares, 
assim como não há uma oposição dicotômica e irreconciliável entre as indefiníveis categorias de "classes populares" e "elites". A investigação das relações entre trabalhadores, Câmara Municipal e outras esferas administrativas joga luz sobre a complexidade dessas relações e seus sujeitos: posturas, resoluções e editais são campos de disputa, passo a passo construídos a partir de interpretações diversas e objeto de tensões entre as diferentes instâncias administrativas, tensões essas das quais esses grupos souberam se aproveitar para fazer suas reivindicações. Além disso, revisitar o tema das eleições no início da República através do cruzamento das listas de eleitores com outros documentos tem mostrado, ao contrário do que se afirmava, 0 interesse de homens e mulheres pobres, livres ou libertos, pela política, associado às promessas de democratização e maior participação popular (Magalhães, 2013; Castellucci, 2010; Mac Cord, 2014; Pinto, 2015; Souza, 2015).

0 envolvimento da arraia miúda pelos primórdios da política republicana que esses trabalhos têm apontado mostra a necessidade de retomada de um diálogo entre a política das ruas e a política dos gabinetes ou dos grandes homens, a política oficial. É necessário ampliar, portanto, o campo da política em que transitavam esses grupos de trabalhadores, e como suas estratégias e experiências de luta e contestação passavam pela formação de interesses comuns num legado que sem dúvida não se perdeu após a abolição da escravidão (1888) e a Proclamação da República (1889), fazendo parte dos processos que informariam os movimentos sociais posteriores.

\section{Os PATRÕes “OS TRATAM de UMA MANEIRA QUE NÃO SE TRATAM ESCRAVOS" - TRABALHO LIVRE NO SÉCULO XIX}

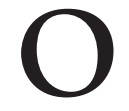

perfil dos trabalhadores no comércio a retalho ao longo do século XIX no Rio de Janeiro era de uma maioria de homens brancos, em grande parte de origem portuguesa, e assim continuou pelo menos até o início do século XX. Se o pequeno comércio era, em várias regiões, reservado aos imigrantes europeus e aos brasileiros "brancos", até meados do século XIX a rua era de negros e negras de ganho vendendo todo tipo de gênero com seus tabuleiros e balaios. No final do século XIX e início do XX havia uma concorrência acirrada entre os vendedores ambulantes e o comércio a retalho, e nesse momento eclodiu em várias cidades a luta dos caixeiros por direitos em novos moldes (Santos, 1974; Duarte, 2000; Popinigis, 2007; Oliveira, 2005; (âmara, 2012; Maciel, 2012).

Ao longo do século XIX, foi frequente a equiparação da situação dos caixeiros à dos escravos, por razões diversas. Em torno de 1850 imigrantes de regiões pobres de Portugal formavam no Rio de Janeiro um proletariado urbano que exercia todo o tipo de funções mal 
remuneradas. Muitos deles escapavam à lavoura e se apinhavam no centro urbano do Rio, tendo como destino principal o comércio a retalho (Alencastro, 1998; Ribeiro, 2002). 0 ano de 1850 foi justamente o da aprovação da lei que proibia o tráfico atlântico de escravos e da aprovação da lei de terras, que comercializava a posse da terra. De um lado, comerciantes e armadores, tendo o capital liberado com o fim do tráfico atlântico de escravos, haviam investido em trabalhadores engajados, e a situação era denunciada como "escravatura branca"; de outro lado, ao longo da segunda metade do oitocentos, tornava-se cada vez mais difícil para homens livres e pobres se estabelecerem como pequenos proprietários (Castro, 2009).2

No "baixo comércio" (sobretudo as casas de secos e molhados, casas de pasto, botequins, armazéns e armarinhos), os caixeiros enfrentavam péssimas condições de trabalho e as ambivalências marcantes de sua posição: trabalhavam até 16 ou 18 horas por dia sem descanso semanal, passando os dias e as noites dentro das próprias casas de comércio, e ficavam sob a vigilância constante do patrão. Esses trabalhadores poderiam receber salários ou soldadas, mas frequentemente passavam anos sem ver a cor do dinheiro, ou porque fossem "aprendizes" ou porque o patrão guardasse seu pecúlio até que fosse suficiente para entrar como capital numa sociedade (finalmente sua "alforria"). Muitas vezes era necessário instaurar um processo pelo não cumprimento do contrato. ${ }^{3}$

A situação do caixeiro como dependente era tal que aos olhos do poder público ele era tão responsável por si mesmo quanto o escravo, como mostra o texto de uma postura de 1852: "Art. 4ํㅡ Os contraventores pagarão a multa de 30.000 réis pela 1av vez, o dobro e oito dias de cadeia nas reincidências. Art. 50 Se o infrator for caixeiro, escravo ou menor paga a multa aquele que o tiver induzido à infração." ${ }^{4}$ (grifo meu) Para os legisladores, tanto caixeiros como escravos eram regidos pela vontade de seus senhores, e, como dependentes que eram, não estavam aptos a responder por si. Talvez por isso a primeira Constituição Brasileira, de 1824, tenha determinado que apenas os primeiros caixeiros e os guarda-livros podiam votar nas eleições primárias. Os demais eram considerados "criados de servir" , o que os excluía do direito de voto ainda que tivessem a renda exigida de 100 mil réis. ${ }^{5}$ Estavam, nesse sentido, equiparados aos escravos e às mulheres: relegados à esfera da domesticidade, tutelados e politicamente incapazes.

Ao que parece, o que permitiu que o trabalho no comércio tivesse muitas faces foram exatamente suas ambivalências: a submissão a uma disciplina pessoal no âmbito privado que possibilitava uma intensa exploração, de um lado, e a possibilidade de ascensão social pela lenta acumulação, de outro. A situação de dependência, os baixos salários, as longas horas 
de trabalho e a falta de regulamentação pelo poder público levava o movimento caixeiral e operário a apontar a situação de penúria em que se encontravam, equiparando-a à condição do escravo. As comparações com a escravidão se alternavam, na Primeira República, com o discurso da militância sobre a proletarização da "classe caixeiral". 0 caixeiro não estava acorrentado ao trabalho, mas deveria ser exemplo de morigeração, economia, fidelidade ao patrão e existência laboriosa.

A metáfora da escravidão era utilizada em várias situações para remeter a formas inaceitáveis de exploração ou organização do processo de trabalho. No combate à exploração do trabalho sexual, por exemplo, o termo internacionalmente utilizado foi "tráfico de escravas brancas"; nos discursos de militantes do movimento operário fabril, descreviam-se as condições de trabalho opressivas das fábricas, manufaturas e oficinas; no caso dos caixeiros, a referência era sobretudo à constante submissão à vontade do patrão que a domesticidade parecia implicar. Mas havia diferenças substanciais para os significados de utilização desse recurso: enquanto serviu para legitimar a luta dos operários e seu apoio aos empregados no comércio em sua ação política, a metáfora da escravidão tendeu a descrever situações de vitimização e passividade para as prostitutas (Popinigis \& Schettini, 2009).

Assim, apesar da experiência da exploração que vivenciavam esses trabalhadores, as posições no comércio a retalho eram disputadas a punhos cerrados por estarem entre os poucos postos de trabalho disponíveis para indivíduos livres com pouca ou nenhuma qualificação (se em muitos anúncios de jornais exigiam-se caixeiros que soubessem ler e escrever até em outras línguas e fazer contas, a maioria aceitava crianças e jovens inexperientes como aprendizes). Além disso, um dos grandes atrativos de ser caixeiro era que o indivíduo poderia ver-se livre do famigerado recrutamento para o Exército. Cobiçados, esses empregos foram motivo da ira de brasileiros contra comerciantes portugueses que só contratavam patrícios, o que frequentemente desembocou em conflitos entre nacionais e estrangeiros no Rio de Janeiro e em Pernambuco ao longo do século XIX (Ribeiro, 1990; Chalhoub, 2008; (âmara, 2012).

No período do pós-abolição, a configuração do mercado de trabalho foi marcada por determinantes raciais e de gênero na construção de hierarquias dentro da própria classe trabalhadora: enquanto as várias atribuições contidas na designação do serviço doméstico continuaram a ser realizadas majoritariamente por afrodescendentes, sobretudo mulheres, e este era desvalorizado e negativado (Souza, 2015), o discurso sobre o comércio despontava como um meio de libertação e modernização no plano coletivo, e de ascensão social no plano pessoal. 


\section{“TrabalheM Eles E VERÃO COMO A CAIXEIRAdA SAIRÁ DO INDIFERENTISMO E CERRARÁ FILEIRAS NA CONQUISTA DE SUAS REELEIÇÕES" - ESTRATÉGIAS DE LUTA}

E m meados do século XIX descrever-se como caixeiro era acionar o pertencimento a uma categoria que reivindicava sua dignidade através do trabalho. Ao mesmo tempo, era também uma forma de distinguir-se das famosas maltas de capoeiras e grupos de vagabundos perigosos que circulavam pelas ruas da cidade, pela possibilidade de ascensão social (Edmundo, 2003: 40).

Os teatros e seus espetáculos tinham lugar privilegiado nas preferências de lazer dos moços do comércio. Por ser portador de uma "missão civilizadora", que deveria "ser extensiva a todas as classes", o teatro servia perfeitamente às suas reivindicações sobre o direito a um "recreio instrutivo e honesto". ${ }^{6}$ Localizado na freguesia da Candelária, na qual havia uma grande concentração de lojas comerciais, o Teatro São Januário pode ser considerado o teatro dos caixeiros até o fim de seus dias, em 1868. No entanto, a presença constante e maciça dos moços do comércio no Teatro São Januário, segundo Sílvia Martins de Souza, acabou ficando estigmatizada pela crítica, tanto pela suposta falta de educação dos frequentadores, quanto pela própria natureza dos espetáculos encenados, apontados como de menor valor artístico (Souza, 2008).

Além do desagrado com a indisciplina dos rapazes, que estariam deixando de lado o serviço para se divertir, havia também o incômodo com a dimensão política dessas reuniões, como mostra uma reclamação publicada no Jornal do Commercio em 1857, afirmando que os caixeiros iam assistir aos ensaios, metiam-se em "intrigas de bastidores" e "formavam partido". ? Francisco Corrêa Vasques, que já fora caixeiro, era um dos mais conhecidos atores do teatro de variedades. Era amigo pessoal de José do Patrocínio, participou ativamente do movimento abolicionista e encenava peças que defendiam a justeza do movimento caixeiral, cuja principal demanda era que os negociantes e proprietários concedessem a folga do domingo para seus empregados (Marzano, 2002: 2). ${ }^{8}$

Já em 1852 o vereador Duque Estrada havia submetido à Câmara Municipal do Rio de Janeiro uma proposta de postura que obrigava ao fechamento das portas das casas de comércio aos domingos, quartas e sextas-feiras santas e Natal. ${ }^{9}$ Ao longo da década de 1860 , a movimentação se fortaleceu, com os trabalhadores se mobilizando para arrecadar assinaturas e costurar acordos com os proprietários para fecharem suas portas, consequentemente liberando-os para a folga nos domingos após o meio-dia e, mais tarde, nos dias santos. Mas a lei do fechamento não era unanimidade entre os proprietários, e muitos viam com maus 
olhos qualquer escapadela daqueles trabalhadores aos seus intermináveis dias de trabalho. Essa questão mobilizava grande parte da imprensa, e era encampada por alguns empresários, atores e autores do teatro.

Ao longo da década de 1870 e 1880 a estratégia mais contundente foi demandar a interferência da Câmara Municipal para formular e aprovar posturas que obrigassem os patrões recalcitrantes a fechar suas portas. ${ }^{10}$ Multiplicados os protestos no final da década de 1870 , a discussão voltou a ocupar espaço na imprensa, sob a forma de um intenso debate sobre a proposta dos caixeiros, com a exposição de argumentos de apoio ou repúdio à regulamentação. Em 8 de dezembro de 1879, finalmente, o presidente da Câmara Municipal, Adolpho Bezerra de Menezes, propôs um projeto de postura que determinava o fechamento do comércio após o meio dia dos domingos e dias santos, prevendo multa e até prisão (exceção para padarias, hotéis e casas de pasto, bilhares e veículos de condução). A "mascateação" ficava também proibida. ${ }^{11}$

Aprovada a postura pela Câmara, houve grande disputa pela intervenção do ministro do Interior, quando o gabinete liberal de Sinimbu já estava sob forte pressão da reforma eleitoral. 0 "motim do vintém", intenso movimento popular contra o aumento do imposto de um vintém sobre os bilhetes, explodiu em janeiro de 1880. 0 movimento foi duramente reprimido, mas o imposto foi revogado e o gabinete caiu (Jesus, 2006; Carvalho, 2007; Terra, 2013). Essa atmosfera de reivindicação e participação da população que tomou as ruas se intensificou ao longo da década de 1880, com a ampliação do movimento republicano e abolicionista (Graham, 1991), enquanto a "mocidade do comércio", como se dizia, ocupava as ruas e fazia suas reivindicações, sem fechar seus canais de diálogo com os poderes públicos (Popinigis, 2007).

Poucos meses depois, entretanto, a Câmara Municipal decidiria pela revogação da postura do fechamento das portas, devido à coleta de assinaturas organizada por um grupo de negociantes da Corte "que se julgavam prejudicados pela postura". ${ }^{12}$ Esses negociantes fundaram a Sociedade União dos Varejistas de Secos e Molhados, com o objetivo explícito de combater a pretensão dos caixeiros. Quase ao mesmo tempo, em 1881, foi fundada a Associação dos Empregados no Comércio (AEC), que aceitava patrões entre os seus sócios. A iniciativa de fundação da AEC foi do imigrante lisboeta, comerciante e ex-caixeiro Vitorino José de Carvalho.

Assim, embora o discurso de seus dirigentes frequentemente corroborasse a ideia da colaboração de classes, o viés classista do movimento estava claro desde o início, quando duas associações - a AEC e a União dos Varejistas - se formaram em torno de objetivos distintos: contra e a favor da regulamentação do horário de trabalho. A AEC se constituiu com o objetivo 
primeiro de lutar pelo fechamento das portas, mas também cumpria as funções de auxílio-mútuo. Posteriormente, outras associações, como a União dos Empregados do Comércio e a Phênix Caixeiral, foram fundadas para lutar pela mesma causa. Muitas vezes criticada por aceitar patrões entre seus sócios, e por sua pompa e circunstância, a AEC foi a associação caixeiral que congregou o maior número de membros no período. ${ }^{13}$

A incansável luta pela aprovação da lei prosseguiu nos anos 1880, bem como o gosto dos moços do comércio pela frequência ao teatro. Desde os primeiros anos da década, a renda de alguns eventos, festas, homenagens e apresentações era revertida para a compra de alforrias de escravos, a respeito das quais fazia-se grande alarde e propaganda. ${ }^{14}$ Os trabalhadores do comércio também reivindicavam a "liberdade" ao Sr. Ministro, pois argumentava-se que os patrões os tratavam "de uma maneira que não se tratam escravos" ${ }^{15}$

Machado de Assis associou a aprovação da lei do fechamento à liberdade da alforria em sua crônica publicada no jornal $A$ Gazeta de Notícias de 10 de novembro de 1888:

Aqui o caso era de um ano, o mesmo que viu a extinção da escravidão. Todas as liberdades são irmãs; parece que, quando uma dá rebate, as outras acodem logo. Aí temos explicado o movimento atual, que, em boa hora, vai sendo praticado em paz e harmonia. Note-se bem que o movimento outrora tinha um caráter meio duvidoso; pedia-se o fechamento das portas aos domingos. 0 domingo, só por si, sem mais nada, é um dia protestante; e o movimento, limitando o descanso a esse dia, como que parecia inclinar à Igreja inglesa. Daí a frieza do clero católico. Agora, porém, a plataforma (se me é lícito dizer uma palavra que pouca gente entende) abrange os domingos e dias santos. Deste modo não se pede só o dia do Senhor, mas esse e os mais que o rito católico estabelece em honra dos grandes mártires ou heróis da fé, e dos fastos da Igreja desde os primitivos tempos.

Bons dias!

Ao afirmar que "todas as liberdades são irmãs" Machado comparava a liberdade jurídica dos escravos à regulamentação das horas e dos horários de trabalho para os caixeiros. Afirmando que "quando uma dá rebate, as outras acodem logo" o autor parecia sugerir que o movimento dos trabalhadores pelo fechamento das portas se houvesse inspirado no movimento abolicionista. Ele elogiava ainda a "paz e harmonia" do movimento, mas ironizava sua demanda pelos dias santos da tradição católica em pleno vigor do movimento republicano.

A intensificação do movimento caixeiral culminaria na aprovação da postura de 1890 sobre o fechamento das portas aos domingos, com uma alteração no art. 2ํㅜ , permitindo assim que as tavernas ficassem abertas. ${ }^{16}$ "Em homenagem aos honrados e distintos empregados do comércio" realizou-se um Grande Festival em comemoração à aprovação da lei no Teatro 
Lucinda. ${ }^{17}$ Sucederam-se elogios e críticas à decisão da Intendência, que sofreu forte oposição. Várias posturas se sucederiam entre meados da segunda metade do século XIX e o início do $X X$, numa queda de braço entre empregados e proprietários que apoiavam a causa e negociantes que se recusavam a fechar suas portas. Estes últimos, apelidados de "carranças" pelos adversários, argumentavam com a "liberdade de comércio" para manter suas portas abertas e se opor à intervenção da municipalidade em seus negócios. Após cada aprovação da postura, o problema era fazer os negociantes contrários a ela cumprirem a determinação, e ficava cada vez mais clara a necessidade da intervenção da municipalidade na formulação de políticas de rígida fiscalização.

Na virada do século tomou corpo novamente o movimento dos empregados no comércio pelo direito ao tempo livre e à instrução. Somando-se às greves que se multiplicavam na primeira década do século XX, em 1906 os caixeiros passaram a percorrer as ruas da cidade em grupos organizados, obrigando os negociantes que mantinham suas lojas abertas a fechá-las. Estavam respaldados pelos acordos feitos com grande parte dos proprietários, através do recolhimento das assinaturas apoiando o fechamento (Popinigis, 2007: 126-137). Os empregados do comércio demonstravam progressivamente seu peso político nas manifestações coletivas em praça pública em que os líderes do movimento e das associações de classe defendiam suas ideias, tão próprias do primeiro período republicano. Em 23 de janeiro de 1911, a Gazeta de Notícias noticiou que uma multidão de 2.000 pessoas teria comparecido ao meeting do Largo de São Francisco de Paula em defesa do fechamento. Suas estratégias se concentravam fortemente no apoio de homens públicos, aos quais não deixavam de agradecer nas publicações a pedido dos periódicos de grande circulação. Depois, os empregados saíam às ruas para comemorar e homenagear os jornais que os apoiavam em suas sedes. Expunham assim ainda mais suas reivindicações e pressionavam os políticos, como se vê por esta nota dos empregados do comércio "que desejam as horas de lazer concedidas a toda gente": "Trabalhem eles e verão como a caixeirada sairá do indiferentismo e cerrará fileiras na conquista de suas reeleições." ${ }^{18}$

Além de republicanos radicais como Silva Jardim e Lopes Trovão, literatos ilustres como o cronista Paulo Barreto (o João do Rio) e Coelho Neto também apoiavam a causa caixeiral. Alguns fizeram da literatura uma frente de luta em prol de causas que consideravam importantes para a transformação social, associando a República ao abolicionismo e ao progresso e a monarquia à escravidão e ao atraso. ${ }^{19}$ Nesse sentido, os bravos moços do comércio encaixavam-se perfeitamente num perfil desejável de cidadãos, dignos representantes do "trabalho livre", branco e masculino, construção que opunha o progresso representado pela República ao atraso associado à escravidão. Os empregados no comércio compunham assim 
uma minoria instruída, pois tinham que saber ao menos ler, escrever e fazer contas, e por vezes falavam línguas estrangeiras.

A postura abrangia diversas categorias de trabalhadores no comércio, proibindo 0 trabalho aos domingos e feriados cívicos, limitando ao máximo de 12 horas o trabalho diário e regulamentando os horários de abertura e fechamento do comércio. ${ }^{20}$ Para as cinco associações de classe que participaram da elaboração do projeto, sua aprovação era uma vitória e uma grande conquista, sobretudo porque possibilitava uma ferramenta legal de luta ao oficializar o limite de horas de trabalho e o horário de fechamento e abertura das portas como direitos sancionados pelo Estado, ainda que na esfera municipal. Assim, as questões políticas e sociais referentes às relações de trabalho no comércio foram irreversivelmente atiradas à esfera pública.

\section{Cidadania E Direitos}

$\mathrm{O}$ s caixeiros do comércio a retalho do Rio de Janeiro - que, em sua maioria, integravam um proletariado formado sobretudo por escravos de ganho, libertos e imigrantes portugueses pobres - estiveram entre as primeiras categorias de trabalhadores a se organizar em associações e a exigir a intervenção dos poderes públicos na mediação de suas lutas por direitos. As condições de exploração, tutela, dependência do patrão, e os muitos anos sem receber remuneração compunham o quadro das relações de trabalho no oitocentos, com uma diversidade de arranjos de trabalho entre a escravidão e a liberdade. 0 fim do tráfico atlântico de escravos em 1850 e o investimento em outras formas de trabalho, como a dos engajados, fizera com que a situação desses jovens portugueses fosse denunciada como "escravidão branca" em incidentes internacionais.

As relações de trabalho nas casas de comércio a retalho, ou o baixo comércio, caracterizavam-se pela situação de dependência e domesticidade que chegava a se equiparar com a dos criados. No entanto, ao longo da segunda metade do século XIX os caixeiros desenvolveram formas de luta coletiva reivindicando diretamente a ação do poder público - a municipalidade - através de cartas e petições, associações, periódicos, peças teatrais e meetings nas ruas e praças. Esses trabalhadores, portanto, compartilhavam, além das condições de trabalho e moradia, uma cultura associativa e reivindicativa.

Na década de 1880 os caixeiros participaram ativamente da arena política e o movimento caixeiral ganhou as ruas junto com vários outros, como o republicano e o abolicionista. Assim, os trabalhadores do comércio se organizaram em torno dos direitos da categoria ao tempo livre e à instrução antes que se articulassem os principais canais reivindicativos do 
movimento operário e nas primeiras décadas do século XX engrossaram o coro das greves de diversas categorias de trabalhadores. Além disso, influenciaram a organização dos empregados no comércio de outras províncias e estados. Não estavam, portanto, alheios à política, nem aos projetos republicanos.

No contexto do pós-abolição, com a adoção de políticas públicas de ocupação da cidade e projetos imigrantistas norteados pelo racismo científico, as transformações no mercado de trabalho foram fortemente definidas pela sua configuração racial e de gênero. No alvorecer do século XX a comparação com a escravidão era um discurso recorrente dos militantes de várias categorias para denunciar a ausência de legislação social e condições de trabalho inaceitáveis, atrelando assim a República a um passado que se queria apagar. Os "honestos moços do comércio" - homens, livres e brancos - se encaixavam bem no discurso de civilização e modernidade de parte dos projetos de cidadania republicana, buscando desvincular-se das relações de dependência pessoal e domesticidade, e criando possibilidades inexistentes para outros grupos de trabalhadores, como os criados e as trabalhadoras do serviço doméstico.

\section{Notas}

1 "Estatutos da Comercial Sociedade Caixeiral: Requerimentos sobre ofício de caixeiros", Rio de Janeiro, 14 de abril de 1826, Arquivo Nacional, Caixa 384, pacote 3; "Fechamento das casas comerciais: proposta do vereador Duque Estrada", 29 de outubro de 1852, AGCRJ, códice 43-3-37.

2 Sobre a denúncia de escravidão dos imigrantes portugueses ver Correio Mercantil, 25/26 de fevereiro de 1857.

3 Para ver dois casos ocorridos em 1906: "Joaquim Pereira dos Santos", Juízo de Direito do Comércio, n.14.817, maço 778, Arquivo Nacional, e "Armando Francisco Ferraz", Juízo de Direito do Comércio, n.399, caixa 2.020, Arquivo Nacional.

4 AGCRJ, cod. 43-03-37, 29/10/1852.

5 Constituição Política do Império do Brasil, elaborada por um Conselho de estado e outorgada pelo Imperador D. Pedro I em 25.03.1824. Capítulo VI - Das eleições, Art.92, parágrafo III. Disponível em http://www. planalto.gov.br/ccivil_03/constituicao/constituicao24.htm. Acessado em: 28 de fev. de 2015.

6 Jornal do Commercio, 05/06/1855.

7 "A classe caixeiral", Jornal do Commercio, 25 /09/1957.

8 "O Advogado dos caixeiros", A Vida Fluminense, 05/02/1870.

9 Proposta datada de 29/10/1852. AGCRJ, cod. 43-03-37. 
10 "Fechamento das casas commerciaes: aos domingos e em dias santificados, representação dos caixeiros das casas commerciaes da praça do Rio de Janeiro, 1870", AGCRJ, códice 43-3-38.

11 O Mercantil, 4/02 e 25/02/1880.

12 O Mercantil, 12/06/1880.

$13 \mathrm{Em} 1900$ a AEC tinha em torno de 15.000 associados e seus diretores gabavam-se afirmando que ela era "a mais poderosa e opulenta corporação beneficente existente no Brasil", segundo notícia publicada num periódico cujo redator-chefe era Ruy Barbosa: A Imprensa, 22/09/1900.

14 "Esther de Carvalho entrega carta de liberdade oferecida pela classe comercial", Gazeta de Notícias, 08/12/1882; "Grande festa bazar em benefício de um escravo", Gazeta de Notícias, 03/03/1883.

15 "Fechamento das portas - ao Exmo. Snr. Ministro do Império", Gazeta de Notícias, 21/02/1880.

16 Código de posturas: leis, decretos, editais e resoluções da intendência municipal do Distrito Federal - Compilação feita por ordem da Prefeitura, pela repartição do Arquivo Geral - Prefeito: Dr. Henrique Valadares - Ed. de 1894, AGRJ; Gazeta de Notícias, 15/11/1890.

17 Título do vaudeville representado por Vasquez na ocasião. Gazeta de Notícias, 23/11/1890.

18 Gazeta de Notícias, 14/06/1909.

19 Antônio da Silva Jardim, "Fechamento das portas: conferência pública na cidade do Rio de Janeiro, em 27 de outubro de 1880, no Imperial Teatro São Pedro D'Alcântara", in Discursos, opúsculos, manifestos. Introdução de Barbosa Lima Sobrinho. Rio de Janeiro, UFF, 1973; Homenagem a Paulo Barreto, Gazeta de Notícias, 29/09/1909. 0 cronista, que era "ilustre sócio benemérito" da União dos Empregados do Comércio, foi, segundo o anúncio publicado no jornal, "iniciador da propaganda pelo fechamento das portas". Gazeta de Notícias, 03/06/1911.

20 AEC, "Recepção em homenagem ao Exmo. Snr. Prefeito do Districto Federal e ao Conselho Municipal em 20 de Janeiro de 1912 para comemorar a lei do Fechamento das portas", Biblioteca Nacional, sessão de obras gerais, II-164, 4, 28, n.10.

\section{REFERÊNCIAS BIBLIOGRÁFICAS}

ABREU, M. Meninas perdidas: os populares e o cotidiano do amor no Rio de. Janeiro da Belle Époque. Rio de Janeiro: Paz e Terra, 1989.

ABREU, M.; GOMES, A. C. A nova "Velha" República: um pouco de história e historiografia. Revista Tempo, Niterói, UFF, v. 13, n. 26, 2009.

ALENCASTRO, L. F. de. Proletários e escravos: imigrantes portugueses e cativos africanos no Rio de Janeiro, 1850-1872. Novos Estudos - Cebrap, São Paulo, n. 21, 1988, p. 30-56.

BATALHA et al. Culturas de classe - identidade e diversidade na formação do operariado. Campinas: Ed. da Unicamp, 2004. 
CÂMARA, B. A. D. 0 retalho do comércio: a política partidária, a comunidade portuguesa e a nacionalização do comércio a retalho - Pernambuco (1830-1870). Tese de doutorado, UFPE, 2012.

CARDOSO. F. H. Situação e composição social do proletariado brasileiro, Sociologie du Travail, n. 4, 1961.

CARVALHO, J. M. de. A Guerra do vintém. Revista de História, 09/09/2007. Disponível em: http://www.revistadehistoria.com.br/secao/capa/a-guerra-do-vintem\#enviar_amigo. Acesso em: 01/10/2014.

CASTELLUCCI, A. A. S. Política e cidadania em Salvador. Revista de História, n. 162 (10 semestre de 2010), 205-241.

CASTRO, H. M. de. Das cores do silêncio: os significados da liberdade no sudeste escravista, Brasil século XIX. Rio de Janeiro: Nova Fronteira, 1998.

—. Raça e cidadania no crepúsculo da modernidade escravista no Brasil. In: GRINBERG, K. e SALLES, R. (org.). O Brasil Imperial, vol. III: 1870-1889. Rio de Janeiro: Civilização Brasileira, 2009.

CHALHOUB, S. Visões da liberdade: uma história das últimas décadas da escravidão na corte. São Paulo: Companhia das Letras, 1990.

_. Trabalho, lar e botequim - o cotidiano dos trabalhadores no Rio de Janeiro da belle époque. 2a ed. Campinas: Ed. da Unicamp, 2001.

e SILVA, F. T. da. Sujeitos no imaginário acadêmico: escravos e trabalhadores na historiografia brasileira desde os anos 1980. Cadernos AEL, 14.26 (2009).

COSTA, C. E. Revisitando 'Família e Transição': família, terra e mobilidade social no pós-abolição: Rio de Janeiro (1888-1940). Revista Brasileira de História, v. 35, n. 69, São Paulo, jan./jun. 2015.

CRUZ, M. C. V. Tradições negras na formação de um sindicato: Sociedade de Resistência dos trabalhadores em trapiche e café, Rio de Janeiro, 1905-1930. Afro-Ásia. CEAO/FFCH/UFBa, 24 (2000).

DUARTE, P. C. B. Clube Caixeiral de Pelotas. A luta pelo fechamento de portas e a construção de uma identidade coletiva - 1879-1900. Histórica. Porto Alegre, n. 4, 2000, p. 159-166.

EDMUNDO, L. O Rio de Janeiro do meu tempo. Brasília: Ed. do Senado Federal, 2003, p.40. Disponível em: http://www2.senado.leg.br/bdsf/bitstream/handle/id/1071/653819.pdf?sequence=4.

FARIAS, J., GOMES, F.,e XAVIER, G. Mulheres negras no Brasil escravista e do pós-emancipação. São Paulo: Ed. Selo Negro, 2012.

FORTES et al. Na luta por direitos-Estudos recentes em História social do Trabalho. Campinas: Ed. da Unicamp, 1999.

GOMES, Â. de C. Questão social e a historiografia no Brasil do pós 1880: notas para um debate. Estudos Históricos, 34 (2004), p.157-186.

GOMES, F. dos S. A hidra e os pântanos: mocambos, quilombos e comunidades de fugitivos no Brasil (séculos XVII-XIX). São Paulo: Ed. Unesp, 2005.

GOMES, F. e NEGRO, A. Além das senzalas e das fábricas: uma história social do trabalho. Tempo Social, 18, n.1, 2006. 
GRAHAM, S. L. 0 motim do vintém e a cultura política no Rio de Janeiro - 1880. Revista Brasileira de História. São Paulo, v.10, n.20, mar./ago. 1991.

HALL, M. M. \& PINHEIRO, P. S. Alargando a história da classe operária. Remate de Males, v.5, p. 96-120, 1985.

JESUS, R. P. de. A Revolta do Vintém e a crise na monarquia. História Social, Campinas, n. 12, 2006.

KOVARICK, L. Trabalho e vadiagem - a origem do trabalho livre no Brasil. São Paulo: Brasiliense, 1987.

LARA, S. Escravidão, cidadania e história do trabalho no Brasil. Projeto História, n.16, 1988, p. 25-38.

LOPES, J. S. L. Vapor do diabo: o trabalho dos operários do açúcar. Rio de Janeiro: Paz e Terra, 1976.

MAC CORD, M. Imperial sociedade dos artistas mecânicos e liberais: mutualismo, cidadania e a reforma eleitoral de 1881 no Recife. In: Organizar e proteger - trabalhadores, associações e mutualismo no Brasil (séculos XIX e XX). Campinas: Ed. da Unicamp, 2014.

MACIEL, O. B. A. M. A perseverança dos caixeiros: o mutualismo dos trabalhadores no comércio em Maceió (1879-1917). Recife: EDUFPE, 2012.

MACHADO, M. H. P. O plano e o pânico: os movimentos sociais na década da abolição. São Paulo: Cia. Das Letras, 1998.

MACHADO, P. P. Lideranças do Contestado: a formação e atuação das chefias caboclas (1912-1916). Campinas: Ed. da UNICAMP, 2004.

MAGALHÃES, M. de S. Tensão e conciliação na política: o poder de veto e a questão do funcionalismo municipal (Capital Federal, 1892-1902). Revista Mundos do Trabalho, v.5, n. 9 (2013).

MAMIGONIAN, B. Revisitando o problema da 'transição para o trabalho livre' no Brasil: a experiência de trabalho dos africanos livres. In: FLORENTINO, Manolo (ed.). Tráfico, cativeiro e liberdade: Rio de Janeiro, séculos XVII-XIX. Rio de Janeiro: Civilização Brasileira, 2005, p. 389-417.

MARZANO, A. 0 ator Vasques, a crônica teatral, a massificação da cultura e a aceitação de um cômico nos meios intelectuais no Rio de Janeiro (1839-189). X Encontro Regional de História, Anpuh-RJ, UERJ, 2002, p.2.

MATTOS, M. B. Escravizados e livres - experiências comuns na formação da classe trabalhadora carioca. Rio de Janeiro: Bom Texto, 2008.

NASCIMENTO, Á. Cidadania, cor e disciplina na revolta dos marinheiros de 1910. Rio de Janeiro: Mauad/ Faperj, 2008.

OLIVEIRA, L. E. de. Os empregados no comércio de Juiz de Fora e sua luta pelo descanso dominical (1880-1905). Anais do Colóquio do LAHES. Juiz de Fora, 13 a 16 de 2005.

PEREIRA, L. A. de M. Barricadas na academia: literatura e abolicionismo na produção do jovem Coelho Netto. Tempo, Rio de Janeiro, n.10, 2000, p. 15-37.

- As barricadas da saúde - vacina e protesto popular no Rio de Janeiro da Primeira República. São Paulo: Fundação Perseu Abramo, 2002. 
PINTO, A. F. M. Caminhos da cidadania: trabalhadores de baixo prestígio e alistamento eleitoral na freguesia da Sé em São Paulo, 1890-1892. Revista do AGCRJ, 2015.

POPINIGIS, F. Proletários de casaca - empregados no comércio carioca (1850-19011).Campinas: Ed. da UNICAMP, 2007.

e SCHETTINI C. (orgs.) Dossiê: Perspectivas de gênero nos mundos do trabalho. Revista Mundos do Trabalho, v.1, n.2, 2009.

REIS, João José. Rebelião escrava no Brasil. A história do levante dos malês (1835). São Paulo: Brasiliense, 1986.

e SILVA, E. Negociação e conflito. A resistência negra no Brasil escravista. São Paulo: Cia das Letras, 1989.

RIBEIRO, G. S. Mata galegos: os portugueses e os conflitos de trabalho na República Velha. São Paulo: Brasiliense, 1990.

A liberdade em construção: identidade nacional e conflitos antilusitanos no Primeiro Reinado. Rio de Janeiro: Relume Dumará, 2002.

SADER, E., PAOLI, M. C. e TELLES, V. Pensando a classe operária: os trabalhadores sujeitos ao imaginário acadêmico. Revista Brasileira de História, n. 6, 1983.

SALGUEIRO, M. A. (org.). A república e a questão do negro no Brasil. Rio de Janeiro: Museu da República, 2005.

SANTOS, M. A. da S. Os caixeiros da Bahia: seu papel conservador na Primeira República. Dissertação de Mestrado, Salvador, Ufba, 1974.

SCHETTINI, C. "Que tenhas teu corpo": uma história social da prostituição. Rio de Janeiro: Arquivo Nacional, 2006.

e TERRA, P. (orgs.). Dossiê "Trabalhadores e poder municipal". Revista Mundos do Trabalho, v.5, n.9, 2013.

SILVA, M. O. L. da. Quotidiano e poder em São Paulo no século XIX. São Paulo: Brasiliense, 1984.

SLENES, R. Na senzala, uma flor. Esperanças e recordações na formação da família escrava - Brasil Sudeste, século XIX. 2ª ed. Campinas: Editora da Unicamp, 2011.

SOARES, L. C. O "povo de Cam" na capital do Brasil. Rio de Janeiro: FAPERJ, 2007.

SOIHET, R. Condição feminina e formas de violência. Mulheres pobres e ordem urbana (1890-1920). Rio de Janeiro: Forense Universitária, 1989.

SOUZA, F. "Negro não pode ser conservador": a política nos talhos do mercado público do Recife nas décadas finais da escravidão. Dossiê: "Negociações municipais: trabalho na cidade", Revista do AGCRJ, 2015.

SOUZA, F. F. de Os intendentes municipais, os criados de servir e a criação da matrícula geral do serviço doméstico (Capital Federal, 1895-1896). Revista do ACRJ, 2015/1. 
SOUZA, R. S. Tudo pelo trabalho livre! Trabalhadores e conflitos no pós-abolição (Bahia 1892-1909). Salvador/ São Paulo: Ed. UFBA/Fapesp, 2011.

SOUZA, S. M. de. Cultura e política no Rio de Janeiro: os caixeiros e o teatro de São Januário na segunda metade do século XIX. LPH Revista de História. Departamento de História (DEHIS), Instituto de Ciências Humanas e Sociais, Universidade Federal de Ouro Preto, ano 18, n.18, 2008.

TERRA, P. C. Cidadania e trabalhadores: cocheiros e carroceiros no Rio de Janeiro (1870-1906). Rio de Janeiro: Prefeitura do Rio/Casa Civil/Arquivo Geral da Cidade do Rio de Janeiro, 2013. 